\title{
Factors Associated with Indacaterol Response in Tuberculosis-Destroyed Lung with Airflow Limitation
}

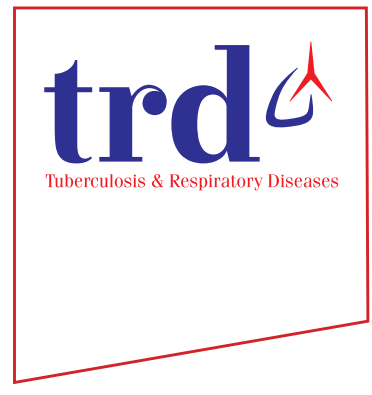

\author{
Tae Hoon Kim, M.D., Ph.D. ${ }^{1,2}$, Chin Kook Rhee, M.D., Ph.D. ${ }^{3}$ and Yeon-Mok Oh, M.D., Ph.D. ${ }^{1}$ (D) \\ ${ }^{1}$ Department of Pulmonary and Critical Care Medicine, Asan Medical Center, University of Ulsan College of Medicine, Seoul, \\ ${ }^{2}$ Department of Internal Medicine, CHA Bundang Medical Center, CHA University, Seongnam, ${ }^{3}$ Division of Pulmonary, Allergy \\ and Critical Care Medicine, Department of Internal Medicine, Seoul St. Mary's Hospital, College of Medicine, The Catholic \\ University of Korea, Seoul, Korea
}

Background: Pulmonary tuberculosis can result in anatomical sequelae, and cause airflow limitation. However, there are no treatment guidelines for patients with a tuberculosis-destroyed lung. Recently, indacaterol effectiveness in chronic obstructive pulmonary disease (COPD) patients with Tuberculosis history (INFINITY) study revealed indacaterol provided bronchodilation and symptom improvement in COPD patients with a tuberculosis-destroyed lung.

Methods: We conducted a post-hoc subgroup analysis of the randomized controlled trial, the INFINITY study, to determine factors associated with indacaterol response in a tuberculosis-destroyed lung with airflow limitation. Data from 68 patients treated with inhaled indacaterol, were extracted and analyzed. Factors associated with the response of forced expiratory volume in one second $\left(\mathrm{FEV}_{1}\right)$ to indacaterol treatment, were determined using linear regression analysis.

Results: Of 62 patients included, $68 \%$ were male, and $52 \%$ had history of cigarette smoking. Patients revealed mean FEV of $50.5 \%$ of predicted value with mean improvement of $81.3 \mathrm{~mL}$ in $\mathrm{FEV}_{1}$ after indacaterol treatment for 8 weeks. Linear regression analysis revealed factors associated with response of $\mathrm{FEV}_{1}$ to indacaterol included a short duration of smoking history, and high short-acting bronchodilator response. When patients with history of smoking were excluded, factors associated with response of $\mathrm{FEV}_{1}$ to indacaterol included high short-acting bronchodilator response, and poor healthrelated quality of life score as measured by St. George's Respiratory Questionnaire for COPD.

Conclusion: In a tuberculosis-destroyed lung with airflow limitation, short-acting bronchodilator response and smoking history can play a critical role in predicting outcomes of indacaterol treatment.

Keywords: Tuberculosis; Pulmonary Disease, Chronic Obstructive; Indacaterol; Smoking

Address for correspondence: Yeon-Mok Oh, M.D., Ph.D.

Department of Pulmonary and Critical Care Medicine, Asan Medical Center, University of Ulsan College of Medicine, 88 Olympic-ro 43-gil, Songpa-gu, Seoul 05505, Korea

Phone: 82-2-3010-3136, Fax: 82-2-3010-4650

E-mail:ymoh55@amc.seoul.kr

Received: Jun. 12, 2018

Revised: Aug. 13, 2018

Accepted: Sep. 11, 2018

(c) It is identical to the Creative Commons Attribution Non-Commercial License (http://creativecommons.org/licenses/by-nc/4.0/).

Copyright (c) 2019

\section{Introduction}

Tuberculosis is the leading cause of death from a single infectious agent. In 2016, an estimated 10.4 million people fell ill with tuberculosis; and its global mortality was estimated at 1.3 million human immunodeficiency virus (HIV)-negative people and 0.37 million HIV-positive people ${ }^{1}$. Pulmonary tuberculosis can result in anatomical sequelae, and cause deterioration of lung functions ${ }^{2-4}$. A study has reported significant pulmonary impairments in more than half of patients treated for tuberculosis ${ }^{5}$. The patients with tuberculosis sequelae are thought to be a significant contributor to chronic obstructive pulmonary disease (COPD) population ${ }^{6}$.

Unfortunately, there are no treatment guidelines for patients with tuberculosis-destroyed lung. In tuberculosis-endemic 
areas, some patients with tuberculosis-destroyed lung may be diagnosed with and treated for COPD because of airflow limitations. A recent study suggests that follow-up care after the completion of tuberculosis treatment is important along with an overall improvement in treatment strategies ${ }^{6}$. A previous report suggested that the inhaled tiotropium may lead to improvement in patients with tuberculosis-destroyed lung ${ }^{7}$. The indacaterol effectiveness in COPD patients with Tuberculosis history (INFINITY) study showed that, relative to placebo, inhaled indacaterol $150 \mu \mathrm{g}$ once-daily provided bronchodilation and symptom improvement in COPD patients with tuberculosis-destroyed lung ${ }^{8}$. However, the clinical factors related to the treatment response to indacaterol were not thoroughly explained in the study ${ }^{8}$. Thus, the study described here aims to determine the factors associated with the response to indacaterol treatment in tuberculosis-destroyed lung with airflow limitation.

\section{Materials and Methods}

\section{Study design and patients}

This post-hoc analysis used data collected in the previously reported INFINITY study ${ }^{8}$. The objective of this study was to determine the factors associated with response to indacaterol $150 \mu \mathrm{g}$ once-daily in patients with tuberculosis-destroyed lung and moderate-to-severe airflow limitation. The treatment response was evaluated by the change from baseline in trough forced expiratory volume in 1 second $\left(\mathrm{FEV}_{1}\right)$ at week 8 of indacaterol treatment.

Briefly, the INFINITY study was a multicenter, randomized, double-blind, placebo-controlled, 8-week trial conducted in South Korea. Eligible patients were aged $\geq 19$ years, had moderate-to-severe airflow limitation (post-bronchodilator $\mathrm{FEV}_{1}$ / forced vital capacity $[\mathrm{FVC}]<0.7$, and post-bronchodilator $\mathrm{FEV}_{1}$ $\geq 30 \%$ and $<80 \%$ of predicted values), and a history of tuberculosis with no change in the chest radiologic test over the past 1 year, regardless of smoking history. All patients had at least one finding of destroyed parenchyma, including lung volume loss, bronchovascular distortion, fibrosis, and bronchiectasis. Exclusion criteria included a history of asthma, respiratory infection or COPD worsening within the previous 6 weeks. After screening, eligible patients were randomized to either a placebo or treatment groups. The treatment group $(\mathrm{n}=68)$ received once-daily indacaterol $150 \mu \mathrm{g}$ through the Breezhaler device (Novartis Pharma AG, Stein, Switzerland) for 8 weeks.

Because this study is a post-hoc analysis using the data from the previous clinical trial, written informed consent was waived. The study protocol was approved by the Institutional Review Board of Asan Medical Center (2018-0509).

\section{Statistical analysis}

We compared characteristics of study subgroups using the unpaired t-test for continuous variables and Fisher exact test for categorical variables. We tested the correlation between the response of $\mathrm{FEV}_{1}$ to indacaterol treatment and the subtypes of leukocytes or parameters of lung functions, using the Pearson's correlation coefficient.

To determine the factors associated with the response of $\mathrm{FEV}_{1}$ to indacaterol treatment, we performed linear regression analysis. Variables identified as significant in univariate analysis were additionally evaluated for the risk-adjusted relationship with the response of $\mathrm{FEV}_{1}$. The multivariate analysis was processed for seven factors, including age, sex, body mass index (BMI), smoking history (pack-years), spirometry finding $\left(\mathrm{FEV}_{1}, \%\right.$ of predicted value), short-acting bronchodilator response, and St. George's Respiratory Questionnaire for COPD (SQRQ-C), using the enter and stepwise backward elimination method.

Statistical analyses were performed using the SPSS version 24.0 (IBM Corp., Armonk, NY, USA). Data are expressed as number (\%) or mean \pm standard deviation, and a p-value of $<0.05$ was considered statistically significant.

\section{Results}

\section{Characteristics of patients}

We analyzed 62 patients, who completed the study, among the 68 patients in the indacaterol treatment group. Therefore, baseline characteristics were similar to data of the original report ${ }^{8}$. Table 1 summarizes the baseline characteristics of the study population. The mean age of patients was 64.6 years, $67.7 \%$ were males, and the overall mean BMI was $21.6 \mathrm{~kg} /$ $\mathrm{m}^{2}$. Overall, 32 patients $(51.6 \%)$ had a smoking history with a mean of 34.9 pack-years. There were only four reports of exacerbations within the previous year (6.5\%). Radiologically, lung volume loss (88.7\%) was the most common finding, followed by fibrosis (66.1\%), bronchovascular distortion (51.6\%), and bronchiectasis (50\%).

Characteristics of lung function were as follows: mean FVC, $2.58 \mathrm{~L}$ (72.3\% predicted) and $\mathrm{FEV}_{1}, 1.32 \mathrm{~L}$ (50.5\% predicted). The reversibility of $\mathrm{FEV}_{1}$ by short-acting bronchodilator was $103.2 \mathrm{~mL}$ (mean). After inhaled indacaterol treatment for 8 weeks, the improvement of $\mathrm{FEV}_{1}$ was calculated to be $81.3 \mathrm{~mL}$ (mean). The overall mean baseline dyspnea index focal score was calculated to be 7.3; COPD assessment test score, 15.4; and SGRQ-C score, 37.9.

\section{Factors related with the response to indacaterol}

Table 2 shows the clinical factors associated with the re- 
Table 1. Baseline demographic and clinical characteristics

\begin{tabular}{|lc|}
\hline & Value \\
\hline Age, $y r$ & $64.6 \pm 10.8$ \\
\hline Male sex & $42(67.7)$ \\
\hline BMI, $\mathrm{kg} / \mathrm{m}^{2}$ & $21.6 \pm 3.4$ \\
\hline Ever smokers & $32(51.6)$ \\
\hline Smoking duration, pack-years & $34.9 \pm 27.2$ \\
\hline COPD exacerbation in previous years & $4(6.5)$ \\
\hline Radiologic findings & \\
\hline Lung volume loss & $55(88.7)$ \\
\hline Bronchovascular distortion & $32(51.6)$ \\
\hline Fibrosis & $41(66.1)$ \\
\hline Bronchiectasis & $31(50.0)$ \\
\hline Pulmonary functions & \\
\hline FVC, $L$ & $2.58 \pm 0.73$ \\
\hline FVC, \% of predicted value & $72.3 \pm 13.2$ \\
\hline FEV ${ }_{1}$ L & $1.32 \pm 0.39$ \\
\hline FEV ${ }_{1}, \%$ of predicted value & $50.5 \pm 11.9$ \\
\hline Bronchodilator response $\left(\mathrm{FEV}_{1}\right), \mathrm{mL}$ & $103.2 \pm 96.0$ \\
\hline FEV ${ }_{1} /$ FVC, $\%$ & $52.1 \pm 9.9$ \\
\hline Symptom scores & \\
\hline BDI focal score & $3.3 \pm 2.1$ \\
\hline CAT score & $15.4 \pm 7.6$ \\
\hline SGRQ-C total score & \\
\hline
\end{tabular}

Values are presented mean \pm standard deviation or number $(\%)$. BMI: body mass index; COPD: chronic obstructive pulmonary disease; FVC: forced vital capacity; $\mathrm{FEV}_{1}$ : forced expiratory volume in 1 second; Bronchodilator response: bronchodilator response by short-acting bronchodilator; BDI: baseline dyspnea index; CAT: COPD assessment test; SGRQ-C: St. George's Respiratory Questionnaire for COPD. sponse of $\mathrm{FEV}_{1}$ to indacaterol treatment. In a univariate analysis, the response amount of $\mathrm{FEV}_{1}$ to indacaterol treatment was associated with smoking history $(\mathrm{p}=0.021)$ and short-acting bronchodilator response $(\mathrm{p}<0.001)$. The response of $\mathrm{FEV}_{1}$ by indacaterol treatment demonstrated statistically significant positive correlation with the amount of short-acting bronchodilator response in $\mathrm{FEV}_{1}(\rho=0.385, \mathrm{p}=0.002 ; \mathrm{r}=0.443, \mathrm{p}<0.001)$ (Figure 1) and smoking history in pack-years $(\mathrm{r}=-0.292$, $\mathrm{p}=0.021$ ) (Figure 1). However, age, sex, BMI, FEV ${ }_{1}$, and SGRQ$\mathrm{C}$ score did not affect the response of $\mathrm{FEV}_{1}$ to treatment with indacaterol in linear regression analysis. Risk-adjusted analysis revealed that indacaterol response was mostly associated with a short smoking history $(\mathrm{p}=0.018)$, and high short-acting bronchodilator response $(\mathrm{p}=0.004)$. Based on the multivariate analyses using the stepwise backward elimination method, this study also demonstrated that indacaterol response was independently associated with two factors: smoking history $(\mathrm{p}=0.016)$, and baseline short-acting bronchodilator response $(\mathrm{p}<0.001)$.

3. Factors related with the response to indacaterol: subgroup analysis according to cigarette smoking

Table 3 presents a comparison of smokers and nonsmokers, in terms of clinical factors associated with response to indacaterol treatment. In smokers, short smoking history $(\mathrm{p}=0.019)$ and high short-acting bronchodilator response $(p=0.045)$ were associated with indacaterol response. However, in nonsmokers, a worse score in health-related quality of life by SGRQ-C $(\mathrm{p}<0.001)$, and higher short-acting bronchodilator response $(\mathrm{p}=0.001)$ were related to the response to indacaterol. While $96.9 \%$ of smokers were males, only $36.7 \%$ of nonsmokers were males. Thus, we analyzed 42 males in total. Both groups had similar clinical and radiologic features. However, the smokers had a mean smoking history of 35.4 pack-years, and lower SGRQ-C score (38.8 \pm 16.1 vs. $23.5 \pm 14.8$,

Table 2. Factors associated with the response of $\mathrm{FEV}_{1}$ to indacaterol treatment

\begin{tabular}{|c|c|c|c|c|c|c|}
\hline & \multicolumn{3}{|c|}{ Univariate } & \multicolumn{3}{|c|}{ Multivariate } \\
\hline & Beta & Standard error & p-value & Beta & Standard error & p-value \\
\hline Age & -1.524 & 1.920 & 0.431 & 0.019 & 1.847 & 0.992 \\
\hline Male sex & 42.381 & 43.969 & 0.339 & -8.367 & 48.728 & 0.864 \\
\hline BMI, kg/m² & 6.579 & 6.136 & 0.288 & 3.389 & 5.573 & 0.546 \\
\hline Smoking history, pack-year & -1.804 & 0.764 & $0.021^{*}$ & -2.169 & 0.888 & $0.018^{*}$ \\
\hline $\mathrm{FEV}_{1}, \%$ pred. & -2.017 & 1.736 & 0.250 & 1.487 & 1.788 & 0.409 \\
\hline $\operatorname{BDR}\left(\mathrm{FEV}_{1}\right), \mathrm{mL}$ & 0.747 & 0.195 & $<0.001^{* * *}$ & 0.654 & 0.219 & $0.004^{* *}$ \\
\hline SGRQ-C & 2.052 & 1.087 & 0.064 & 1.684 & 1.202 & 0.167 \\
\hline
\end{tabular}

${ }^{*} \mathrm{p}<0.05,{ }^{* *} \mathrm{p}<0.01,{ }^{* * *} \mathrm{p}<0.001$.

$\mathrm{FEV}_{1}$ : forced expiratory volume in 1 second; BMI: body mass index; BDR: short-acting bronchodilator response; SGRQ-C: St. George's Respiratory Questionnaire for chronic obstructive pulmonary disease. 

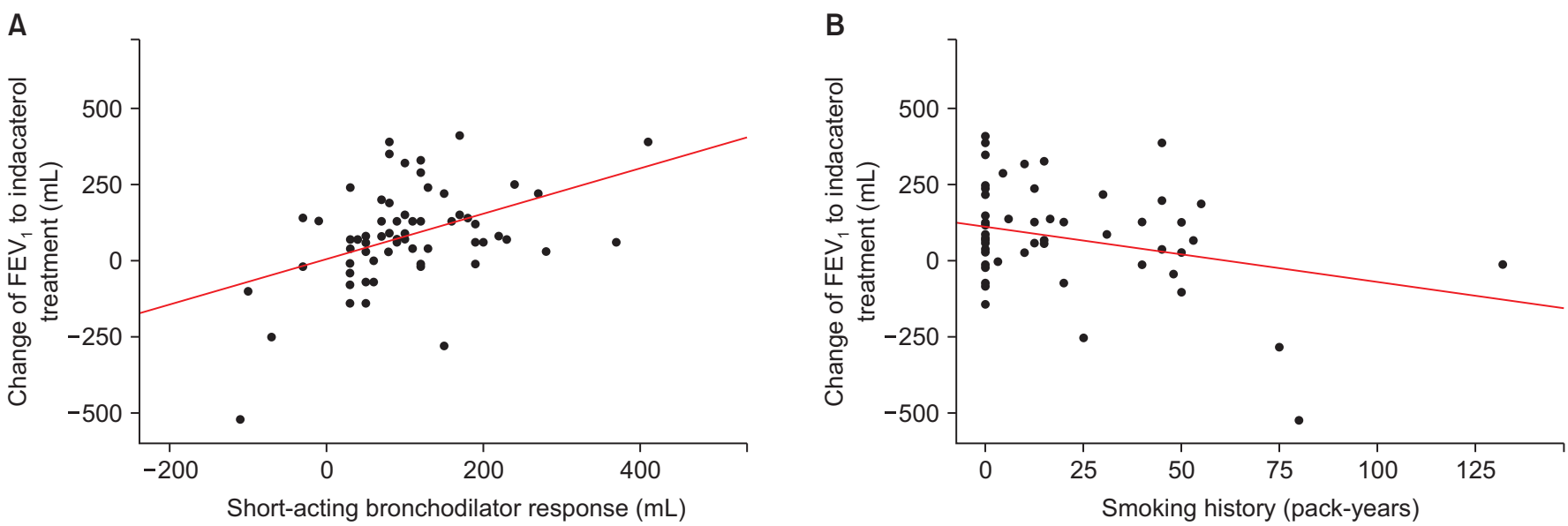

Figure 1. Correlation between short-acting bronchodilator response (A) or smoking history (B) and the response of forced expiratory volume in 1 second $\left(\mathrm{FEV}_{1}\right)$ to indacaterol treatment.

Table 3. Factors associated with the response of $\mathrm{FEV}_{1}$ to indacaterol treatment according to smokers and non-smokers

\begin{tabular}{|c|c|c|c|c|c|c|}
\hline & \multicolumn{3}{|c|}{ Smokers $(n=32)$} & \multicolumn{3}{|c|}{ Nonsmokers $(\mathrm{n}=30)$} \\
\hline & Beta & Standard error & p-value & Beta & Standard error & p-value \\
\hline Age & -4.325 & 2.901 & 0.146 & 1.917 & 2.412 & 0.434 \\
\hline Male sex & 60.645 & 189.513 & 0.751 & 46.220 & 51.977 & 0.381 \\
\hline $\mathrm{BMI}, \mathrm{kg} / \mathrm{m}^{2}$ & 5.496 & 10.722 & 0.612 & 7.141 & 6.915 & 0.311 \\
\hline Smoking history, pack-year & -2.801 & 1.125 & $0.019^{*}$ & & & \\
\hline $\mathrm{FEV}_{1}, \%$ pred. & -3.168 & 2.425 & 0.201 & 0.697 & 2.681 & 0.797 \\
\hline $\operatorname{BDR}\left(\mathrm{FEV}_{1}\right), \mathrm{mL}$ & 0.621 & 0.297 & $0.045^{*}$ & 0.940 & 0.241 & $0.001^{* *}$ \\
\hline SGRQ-C & -0.837 & 2.050 & 0.686 & 3.901 & 0.974 & $<0.001^{* * *}$ \\
\hline
\end{tabular}

${ }^{*} \mathrm{p}<0.05,{ }^{* *} \mathrm{p}<0.01,{ }^{* * *} \mathrm{p}<0.001$.

$\mathrm{FEV}_{1}$ : forced expiratory volume in 1 second; BMI: body mass index; BDR: short-acting bronchodilator response; SGRQ-C: St. George's Respiratory Questionnaire for chronic obstructive pulmonary disease.

$\mathrm{p}=0.010)$. Of the radiologic findings, fibrosis was more common in smokers than nonsmokers ( $80.6 \%$ vs. $36.4 \%, \mathrm{p}=0.019)$.

\section{Relation of radiologic findings with the response to indacaterol}

Supplementary Table S1 summarizes the response of $\mathrm{FEV}_{1}$ to indacaterol treatment based on the radiologic findings. Clinically significant abnormal findings were observed in 52 patients (83.9\%). There was no significant difference in the response of $\mathrm{FEV}_{1}$ to indacaterol treatment between patients with abnormal findings $(15.0 \pm 251.4 \mathrm{~mL})$ and those without abnormal findings $(94.0 \pm 138.2 \mathrm{~mL}, \mathrm{p}=0.159)$. In patients with lung volume loss, the response of $\mathrm{FEV}_{1}$ to indacaterol treatment was $77.3 \pm 153.4 \mathrm{~mL}$; however, there was no difference in patients without lung volume loss $(112.9 \pm 229.7 \mathrm{~mL}, \mathrm{p}=0.703)$. Patients with fibrosis showed a $66.3 \pm 122.6 \mathrm{~mL}$ change in $\mathrm{FEV}_{1}$; however, patients without fibrosis had a $110.5 \pm 220.0$
$\mathrm{mL}$ change in $\mathrm{FEV}_{1}(\mathrm{p}=0.313)$. There was no significant difference between patients with bronchovascular distortion $(100.6 \pm 154.9 \mathrm{~mL})$ and those without bronchovascular distortion $(60.7 \pm 168.9 \mathrm{~mL}, \mathrm{p}=0.337)$. The response of $\mathrm{FEV}_{1}$ to indacaterol treatment was $66.1 \pm 154.8 \mathrm{~mL}$ in patients with bronchiectasis, and this response was similar to patients without bronchiectasis $(96.5 \pm 170.0 \mathrm{~mL}, \mathrm{p}=0.465)$. Overall, 15 patients $(24.2 \%)$ showed all four abnormal radiologic findings with a $42.7 \pm 113.6 \mathrm{~mL}$ change in $\mathrm{FEV}_{1}$.

\section{Discussion}

This post-hoc analysis of the INFINITY study aimed to identify the characteristics of responders to indacaterol $150 \mu \mathrm{g}$ once-daily in patients with tuberculosis-destroyed lung with moderate-to-severe airflow limitation. In the current study, the response of $\mathrm{FEV}_{1}$ to indacaterol treatment demonstrated 
significant positive correlation with short-acting bronchodilator response. Patients with better response to indacaterol treatment exhibited a clinical phenotype with high shortacting bronchodilator response and short duration of tobacco smoking. These data suggest that short-acting bronchodilator response and smoking history can be important factors in predicting the response to indacaterol treatment in patients with tuberculosis-destroyed lung with airflow limitation. Additionally, there were differences in clinical factors between smokers and nonsmokers related to response to indacaterol treatment. In nonsmokers, indacaterol response was associated with short-acting bronchodilator response and SGRQ-C.

Pulmonary tuberculosis can result in airflow obstructions, particularly in those with a long-standing history of the disease, and if the extent of parenchyma involvement is extensive ${ }^{9}$. However, there are no treatment guidelines for patients with tuberculosis-destroyed lung. Recently, the INFINITY study provided some evidence for management of tuberculosis-destroyed lung with airflow limitation. In the currrent study, we determined the factors related to the response to indacaterol treatment in tuberculosis-destroyed lung with airflow limitation. $\mathrm{FEV}_{1}$ reversibility by short-acting bronchodilator was an independent factor associated with the response of $\mathrm{FEV}_{1}$ to indacaterol treatment. In COPD, a shortacting bronchodilator reversibility test has been employed to identify patients with different disease course and has also been used to predict long-term response to bronchodilators ${ }^{10}$. However, most studies suggest that the reversibility to shortacting bronchodilator does not predict long-term response to bronchodilator maintenance therapy because of various confounding effects ${ }^{11-14}$. Nonetheless, the role of reversibility caused by short-acting bronchodilator use was not completely investigated in tuberculosis-destroyed lung with airflow limitation. It has been shown that reversibility in patients with tuberculosis-destroyed lung was significantly poor compared to those with $\mathrm{COPD}^{15}$. This result explained by attributing airflow obstruction in tuberculosis-destroyed lung more to mechanical destruction and stenosis rather than contraction of the smooth muscles of the airway ${ }^{15}$. However, there is still unclear in the clinical role and the mechanism of reversibility in tuberculosis-destroyed lung.

In the current study, heavy-smoking history was another independent factor related to poor response to indacaterol treatment. Tobacco smoking is a major cause of the development of COPD and the risk increases in a dose-dependent manner with the increase in pack-years ${ }^{16}$. The relationship between smoking and the rate of lung function decline has been well established in the general population ${ }^{17}$. However, there is still controversy surrounding the difference in lung function between nonsmoker and smoker COPD patients ${ }^{18-22}$. Furthermore, the role of smoking in patients with tuberculosis-destroyed lung has not been established. Some papers have demonstrated that tuberculosis in smokers results in a severe disseminated clinical course and extensive lung involvement ${ }^{9,23}$. Our study showed that nonsmokers have different clinical features associated with indacaterol response compared with smokers. It has been previously suggested that the sex ratio of each study may impact the study results, as a selection bias, in clinical differences between nonsmoker and smoker COPD patients ${ }^{24}$. Furthermore, our study had a significant difference in sex ratio between smokers and nonsmokers. However, the analysis of male patients showed that smokers had exacerbated symptoms and a higher degree of fibrosis. A previous COPD study have also shown that COPD patients who were smokers had more chronic cough, and sputum than nonsmoker COPD patients ${ }^{24}$. Some studies have demonstrated that smoker COPD patients have a greater incidence of emphysema than nonsmoker COPD patients ${ }^{18,22,24,25}$. However, we could not determine the role of smoking in emphysema. Further investigations are required to evaluate the role of smoking in patients with tuberculosis-destroyed lung with airflow limitation.

Bronchial and parenchymal destruction by tuberculosis induce radiologic changes, including lung volume loss, bronchiectasis, bronchovascular distortion, and fibrotic bands $\mathrm{s}^{26}$. In the current study, we analyzed the relationship between these four common radiologic findings and their response to indacaterol treatment in tuberculosis-destroyed lung with airflow limitation. Although not statistically significant, reduced treatment responses were observed in patients with lung volume loss, fibrosis, and bronchiectasis. Strangely, there was a trend toward improved treatment response with bronchovascular distortion. This difference might be attributed to differences affecting structure and function of the lung, associated vascular complications, and parenchymal or airway lesions. In tuberculosis-destroyed lung, additional studies are still required to determine the ability of various radiologic findings to predict lung functions and treatment responses. A recent study on tuberculosis-destroyed lung showed no differences in the incidence of pleural thickening or bronchiectasis between patients with and without airflow obstruction ${ }^{15}$. Also, pleural thickening did not affect the decline in lung function. However, Jung et al. ${ }^{3}$ reported that inactive tuberculosis lesion, in the upper lobe with dominant, discrete linear or reticular opacities, with or without calcification, on chest X-ray was an important risk factor for determining airflow obstruction.

This study has several limitations. First, it included a small sample size, because it was a post-hoc subgroup analysis used only one arm of the INFINITY study. However, the INFINITY study was conducted as a multicenter, randomized, doubleblind, placebo-controlled study. Thus, the results of this investigation are novel, despite the small sample size. However, a more extensive study is required to predict the response to indacaterol treatment in tuberculosis-destroyed lung with airflow limitation. A second potential limitation could be that not all confounding factors were analyzed, such as biomass 
fuel exposure or socioeconomic status. These factors could affect the progression of airflow obstruction or sequelae of tuberculosis. Third, this study did not reflect the characteristics of tuberculosis-destroyed lung without airflow limitation. As previously mentioned, treatment guidelines for patients with tuberculosis-destroyed lung have not been established. Hence, further investigations are warranted to determine the pharmacological agents and to predict the treatment response for patients with tuberculosis-destroyed lung, regardless of airflow obstruction.

In tuberculosis-destroyed lung with airflow limitation, short-acting bronchodilator response correlates with $\mathrm{FEV}_{1}$ response to inhaled indacaterol treatment. In addition, the improvement of lung function is independently related to short smoking history as well as high short-acting bronchodilator response. In nonsmokers, high short-acting bronchodilator response, and poor health-related quality of life score as measured by SGRQ-C were related to indacaterol response in tuberculosis-destroyed lung with airflow limitation.

\section{Authors' Contributions}

Conceptualization: Oh YM. Methodology: Oh YM, Kim TH. Formal analysis: Oh YM, Kim TH, Rhee CK. Writing - original draft preparation: Kim TH. Writing - review and editing: Oh YM, Rhee CK. Approval of final manuscript: all authors.

\section{Conflicts of Interest}

The authors declare no competing financial interests. The INFINITY study data was generously provided by Novartis, but no financial, statistical, or personal support was provided for this study.

\section{Acknowledgments}

This study was supported by a grant from the Ministry of Health and welfare, Republic of Korea (Grant No. HC16C-2254-010017). We authors thank Novartis Korea Ltd (Seoul, Korea) for providing the INFINITY study data.

\section{Supplementary Material}

Supplementary material can be found in the journal homepage (http://www.e-trd.org).

\section{References}

1. World Health Organization Global tuberculosis report, 2017 [Internet]. Geneva: World Health Organization; 2017 [cited 2018 Apr 1]. Available from: http://appswhoint/ iris/bitstream/handle/10665/259366/9789241565516engpdf?sequence $=1$.

2. Harries AD, Ade S, Burney P, Hoa NB, Schluger NW, Castro JL. Successfully treated but not fit for purpose: paying attention to chronic lung impairment after TB treatment. Int J Tuberc Lung Dis 2016;20:1010-4.

3. Jung JW, Choi JC, Shin JW, Kim JY, Choi BW, Park IW. Pulmonary impairment in tuberculosis survivors: the Korean National Health and Nutrition Examination Survey 2008-2012. PLoS One 2015;10:e141230.

4. Menezes AM, Hallal PC, Perez-Padilla R, Jardim JR, Muino A, Lopez MV, et al. Tuberculosis and airflow obstruction: evidence from the PLATINO study in Latin America. Eur Respir J 2007;30:1180-5.

5. Pasipanodya JG, Miller TL, Vecino M, Munguia G, Garmon R, Bae $S$, et al. Pulmonary impairment after tuberculosis. Chest 2007;131:1817-24.

6. Byrne AL, Marais BJ, Mitnick CD, Lecca L, Marks GB. Tuberculosis and chronic respiratory disease: a systematic review. Int J Infect Dis 2015;32:138-46.

7. Yum HK, Park IN. Effect of inhaled tiotropium on spirometric parameters in patients with tuberculous destroyed lung. Tuberc Respir Dis 2014;77:167-71.

8. Kim CJ, Yoon HK, Park MJ, Yoo KH, Jung KS, Park JW, et al. Inhaled indacaterol for the treatment of COPD patients with destroyed lung by tuberculosis and moderate-to-severe airflow limitation: results from the randomized INFINITY study. Int J Chron Obstruct Pulmon Dis 2017;12:1589-96.

9. Chakrabarti B, Calverley PM, Davies PD. Tuberculosis and its incidence, special nature, and relationship with chronic obstructive pulmonary disease. Int J Chron Obstruct Pulmon Dis 2007;2:263-72.

10. Hanania NA, Celli BR, Donohue JF, Martin UJ. Bronchodilator reversibility in COPD. Chest 2011;140:1055-63.

11. Bleecker ER, Emmett A, Crater G, Knobil K, Kalberg C. Lung function and symptom improvement with fluticasone propionate/salmeterol and ipratropium bromide/albuterol in COPD: response by beta-agonist reversibility. Pulm Pharmacol Ther 2008;21:682-8.

12. Tashkin D, Kesten S. Long-term treatment benefits with tiotropium in COPD patients with and without short-term bronchodilator responses. Chest 2003;123:1441-9.

13. Hanania NA, Sharafkhaneh A, Celli B, Decramer M, Lystig T, Kesten S, et al. Acute bronchodilator responsiveness and health outcomes in COPD patients in the UPLIFT trial. Respir Res 2011;12:6.

14. Burgel PR, Le Gros V, Decuypere L, Bourdeix I, Perez T, Deslee G. Immediate salbutamol responsiveness does not 
predict long-term benefits of indacaterol in patients with chronic obstructive pulmonary disease. BMC Pulm Med 2017;17:25.

15. Rhee CK, Yoo KH, Lee JH, Park MJ, Kim WJ, Park YB, et al. Clinical characteristics of patients with tuberculosis-destroyed lung. Int J Tuberc Lung Dis 2013;17:67-75.

16. Forey BA, Thornton AJ, Lee PN. Systematic review with metaanalysis of the epidemiological evidence relating smoking to COPD, chronic bronchitis and emphysema. BMC Pulm Med 2011;11:36.

17. Kohansal R, Martinez-Camblor P, Agusti A, Buist AS, Mannino DM, Soriano JB. The natural history of chronic airflow obstruction revisited: an analysis of the Framingham offspring cohort. Am J Respir Crit Care Med 2009;180:3-10.

18. Ji W, Lim MN, Bak SH, Hong SH, Han SS, Lee SJ, et al. Differences in chronic obstructive pulmonary disease phenotypes between non-smokers and smokers. Clin Respir J 2018;12:666-73.

19. Lamprecht B, McBurnie MA, Vollmer WM, Gudmundsson G, Welte T, Nizankowska-Mogilnicka E, et al. COPD in never smokers: results from the population-based burden of obstructive lung disease study. Chest 2011;139:752-63.

20. Zhou Y, Wang C, Yao W, Chen P, Kang J, Huang S, et al. COPD in Chinese nonsmokers. Eur Respir J 2009;33:509-18.
21. Ramirez-Venegas A, Sansores RH, Perez-Padilla R, Regalado J, Velazquez A, Sanchez C, et al. Survival of patients with chronic obstructive pulmonary disease due to biomass smoke and tobacco. Am J Respir Crit Care Med 2006;173:393-7.

22. Rezende Goncalves J, Corso Pereira M, Figueiras Pedreira De Cerqueira EM, Oliveira Magro D, Mello Moreira M, Paschoal IA. Severe obstructive disease: similarities and differences between smoker and non-smoker patients with COPD and/ or bronchiectasis. Rev Port Pneumol 2013;19:13-8.

23. Leung CC, Yew WW, Chan CK, Tam CM, Lam CW, Chang KC, et al. Smoking and tuberculosis in Hong Kong. Int J Tuberc Lung Dis 2003;7:980-6.

24. Zhang J, Lin XF, Bai CX. Comparison of clinical features between non-smokers with COPD and smokers with COPD: a retrospective observational study. Int J Chron Obstruct Pulmon Dis 2014;9:57-63.

25. Camp PG, Ramirez-Venegas A, Sansores RH, Alva LF, McDougall JE, Sin DD, et al. COPD phenotypes in biomass smoke- versus tobacco smoke-exposed Mexican women. Eur Respir J 2014;43:725-34.

26. Kim HY, Song KS, Goo JM, Lee JS, Lee KS, Lim TH. Thoracic sequelae and complications of tuberculosis. Radiographics 2001;21:839-58. 
Supplementary Table S1. Responses of $\mathrm{FEV}_{1}$ to indacaterol treatment, according to radiologic findings

\begin{tabular}{|c|c|c|c|c|}
\hline \multicolumn{2}{|c|}{ Radiologic finding } & \multirow{2}{*}{$\begin{array}{r}\text { No. (\%) } \\
7(11.3)\end{array}$} & \multirow{2}{*}{$\begin{array}{c}\delta \mathrm{FEV}_{\mathbf{1}}(\mathrm{mL}) \\
112.9_{ \pm} 229.7\end{array}$} & \multirow{2}{*}{$\begin{array}{c}\mathbf{p} \text {-value } \\
0.703\end{array}$} \\
\hline Without & Lung volume loss & & & \\
\hline With & Lung volume loss & $55(88.7)$ & $77.3 \pm 153.4$ & \\
\hline Without & Bronchovascular distortion & $30(48.4)$ & $60.7 \pm 168.9$ & 0.337 \\
\hline With & Bronchovascular distortion & $32(51.6)$ & $100.6 \pm 154.9$ & \\
\hline Without & Fibrosis & $21(33.9)$ & $110.5 \pm 220.0$ & 0.313 \\
\hline With & Fibrosis & $41(66.1)$ & $66.3 \pm 122.6$ & \\
\hline Without & Bronchiectasis & $31(50.0)$ & $96.5 \pm 170.0$ & 0.465 \\
\hline With & Bronchiectasis & $31(50.0)$ & $66.1 \pm 154.8$ & \\
\hline
\end{tabular}

Values are presented as numbers (\%) and mean \pm standard deviation.

$\mathrm{FEV}_{1}$ : forced expiratory volume in 1 second; $\delta \mathrm{FEV}_{1}$ : change from baseline in trough $\mathrm{FEV}_{1}$ after 8 weeks. 